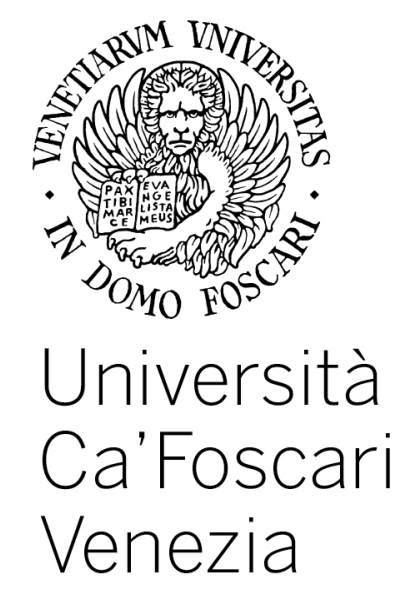

Department
of Management

Working Paper Series

Tatjana Mihailovic, Tiziano Vescovi

and Andrea Pontiggia

The Beauty Ideal in Chinese

Luxury Cosmetics: Adaptation Strategies of Western

Companies

Working Paper n. 7/2017 July 2017

ISSN: 2239-2734

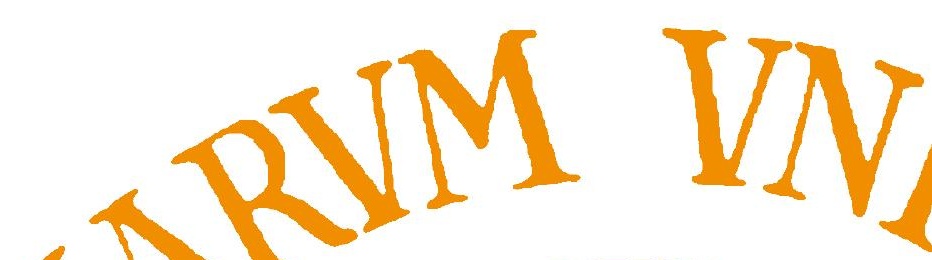


This Working Paper is published under the auspices of the Department of Management at Università $\mathrm{Ca}^{\prime}$ Foscari Venezia. Opinions expressed herein are those of the authors and not those of the Department or the University. The Working Paper series is designed to divulge preliminary or incomplete work, circulated to favour discussion and comments. Citation of this paper should consider its provisional nature. 


\title{
The Beauty Ideal in Chinese Luxury Cosmetics: Adaptation Strategies of Western Companies
}

\author{
Tatjana Mihailovic \\ Tiziano Vescovi \\ Andrea Pontiggia \\ 832268@stud.unive.it \\ vescovi@unive.it \\ pontiggia@unive.it \\ International Management to Asia Lab \\ Department of Management \\ Ca’ Foscari University Venice
}

(June 2017)

\begin{abstract}
The aim of this paper is to determine if the standardization strategies, widely implemented by the luxury companies in international markets, can successuflly adopted in the Chinese Markets. In order to verify this statement, we analyse the luxury cosmetics industry in a market characterized by evident cultural differences. The cultural differences have been studied in term of beauty ideals and consumers' behavior and expectations. We study four western luxury cosmetics companies. Although the first moves were mainly shaped on replication and standardization, the cultural differences force the four western companies to transform their orientation towards adaptation. This finding was partially unexpected and suggests that for specific type of luxury products the adaptation and flexibility are required despite the drift to replicate the standardized marketing strategies. These results are consistent with those of other studies suggesting the need for a balanced approach of standardization and adaptation in managing the international strategies.
\end{abstract}

Keywords: Cross-cultural marketing, International managment, Luxury marketing JEL Classification Numbers: M31

\section{Correspondence to:}

Tiziano Vescovi

Dept. of Management, Università Ca' Foscari Venezia

San Giobbe, Cannaregio 873

30121 Venezia, Italy

e-mail: vescovi@unive.it 


\section{Introduction}

Cosmetics sector is one of the fastest growing and belongs to the top five sectors of consumer goods in China and in thirty years has developed from being nonexistent to becoming the second largest market in the world. The influence of Chinese culture on companies' strategies could be strong. The most influential factor is the fact that Chinese beauty ideal has traditionally differed in large measure from the Western one. Despite Western influence, Eastern beauty criteria could represent an obstacle to a standardized marketing approach. Nevertheless, the Chinese cosmetics market is dominated by Western multinational companies and the luxury segment of the market is the fastest growing. In China there was no market tradition in luxury cosmetics. This has allowed companies to have a different positioning compared to their home markets and to be 2olda $\mathrm{s}$ "luxury", gaining competitive advantage, since luxury usually comprehends uniqueness and differentiation from competitors. Also the concept of accessible luxury is important in China. The brands belonging to accessible luxury have been extremely successful in the latest years. A characteristic of luxury brands is to rely on a standardized strategy because they respond to universal needs and the segmentation of the market is natural. Due to the brand value, adaptive approach has been avoided.

In China self beautification practices were prohibited during Mao's regime and the equality of genres was pursued, coeherently with the idelogy of collectivist society. The nonexistence of domestic industry represented an opportunity for Western companies, attracted by the potential of the chinese market. Today Western companies have the $80 \%$ of the market. However the different beauty ideal, cultural barriers, and the development of domestic and asian players focused specifically to East-Asian women, are changing the competitive positioning of main player of the cosmetics industry.

\section{Global Strategies: Standardization versus Adaptation}

The luxury cosmetics has been analysed as one of most relevant segment of the luxury industry. Every component of the business models (brands, prices, retail, advertising...) seem to communicate to the high-end segment for rich and affluent customers. It follows that we may expect to see a replication of standardization strategies as we observe in different segment of the luxury products. This orientation can be observed and analised looking at the implementation and execution of the global strategies. "Global strategy is defined as the way a company competes in the global market and plays a vital role on determining the performance of a business in the global market. By conceiving a global strategy, management articulates sourcing, R\&D, manufacturing, and marketing must be co-ordinated worldwide. Because marketing assumes the role of interacting directly with the customers marketing strategy is probably the most important component of a firm's global strategy" (Zou, Cavusgli, 1995).

Since more than thirty years on of the crucial strategic choice in the literature on international strategy concerns how firms emphasize global integration and standardization versus differentiation and responsiveness to national/local differences. Prahalad and Doz (1987) described this challenges in term of widely cited global integration-national responsiveness tradeoff. One of the most cited orientation has been the so-called standardization approach. Levitt (1983) sustained that communication, transportation, technology and travel would eradicated country differences and led to universal needs that companies could satisfy by standardized products. It generates differences between multinationals and global companies.

"The global corporation operates with resolute constancy - at low relative cost - as if the entire world (or major regions of it) were a single entity; it sells the same things in the same way everywhere" (Levitt 1983). The biggest advantage of this approach results in economies of scale 
that lower the price and allow high quality products. The competition concentrates on prices, while proposing high quality products.

Contrasting opinions state that "an effective global strategy requires not a single approach, such as product standardization, but a differentiated strategy (Hout, 1982), while Hamel and Prahalad (1994) sustain the need for a diversified portfolio and believe that "a global strategy requires several product varieties, so that investments in technologies, brand names and distribution channels can be shared." Quelch and Hoff (1986) emphasize the importance of being responsive to local market conditions. Bartlett and Ghoshal $(1988 ; 1991)$ sustain that "globalizing and localizing forces work together to transform many industries, and success depends on whether a business can achieve global efficiency and national flexibility simultaneously". Collins (1991) states that "global strategy is dictated by market imperatives, and competitive advantage is derived from implementing a strategy which corresponds to those market imperatives". Bartlett and Ghoshal, 1988; Collis 1991 sustain the competing with multiple strategies in the same global industry is more successful than adopting a single approach.

An approach in which the degree of standardization of responsiveness varies is promoted by Quench and Hoff (1986). Indeed "For most products, the appropriate degree of standardization varies from one element of the marketing mix of a decentralized multinational that wishes to pursue global marketing will often vary from one country to another" (Zoe, Cavusgil, 1995). In the 60's and 70's the attention has been focused on the entry strategies, since the international experience of multinational companies was still low. Douglas and Craig (1989) argue that there is a preinternationalization phase in which the focus is establishing a strong position in the domestic market, and the strategy adopted in the domestic market determines the direction of internationalization. In the initial phase exports are usually the chosen pattern and manufacturing and R\&D are centrally controlled. The costs of entering a new market have to be evaluated considering to which degree a standardized approach can be followed. The choice comprehends choosing which products can be marketed and to which degree the domestic marketing mix can be followed. In 1989 Ohmae has identified three major regions: Europe, USA and Japan and to be competitive global firms should have established strong positions in all three markets. Sammie and Roth (1992) found that there is no relationship between global marketing standardization and a firm's performance, whereas Cavusgil and Zou (1994) find a positive relationship between product adaptation and an export venture's performance. Agreement (Morrison, and Hulland 1995; Hamel and Prahalad 1985; Jain 1989; Levitt 1983; Ohmae 1989; Porter 1986; Yip 1995; Zou and Cavusgil 1996) has been reached in affirming that global marketing strategy plays a critical role in determining a firm's performance in the global market and that "the success of the companies in the twenty-first century will depend on whether it can compete effectively in world markets" (Hax, 1989; Ohmae, 1989).

In the last four decades, a great amount of academic research has been devoted to standardization /adaptation debate. During the 1980s, mainstream articles on this topic concentrated on whether a company should follow a strategy of adaptation to each regional market versus standardization across all national markets (Levitt, 1983).

The similarity of the markets increases and markets become more homogenous, firms could market similar products and services around the world with standardized marketing programs (Hamel and Prahalad 1985; Levitt 1983).

This approach has been critized beacuase underestimate cultural, political, and economic differences between regions.

To carry out the objective of this study, we start with an assessment of the relevant literature followed by the proposed framework covering all dimensions in detail.

Lages et al. (2008) identifies some factors favoring standardization: industrial products instead of consumer products, for which technical specifications are important, facilitates standardization, economies of scale, similarity of customer tastes and consumption models, high barriers to adaptation, ethnocentric orientation. 
On the other hand, supporters of the adaptation enphasize that the cultural differences among countries are crucial. Factors favoring adaptation are: consumer products more influenced by individual taste and fashion; differences in consumer purchasing behavior; regional and local regulations and technical standards; differences of traditions, language, tastes and consumers' habits; polycentric orientationa and adaptation strategies implemented by competitors; different stages of development of foreign and domestic markets.

The contingency approach can be summerized in the following points: "(a) standardization or adaptation should not be seen in isolation from each other, but as two ends of the same continuum, (b) the decision to standardize or adapt the marketing strategy is situation specific, and this should be the outcome of thorough analysis and assessment of the relevant contingency factors prevailing in a specific market at a specific time; and (c) the appropriateness of the selected level of strategy standardization/adaptation should be evaluated on the basis of its impact on company performance in international markets". The issue faced by the international company is to define which the specific strategy elements are feasible or desirable to standardize or adapt, under what conditions, and to what degree (Theodosiou and Leonidou, 2003).

Concerning the internationalization of luxury products, the strategies of the companies follow the standardization path for at least two reasons: a) luxury customers present the same profile, or a very similar one, across every country, being affluent shoppers, globetrollers, sophisticated consumers; b) the brand image should be consistent in every part of the world, being the main asset (Gosh and Varshney 2013). Nevertheless luxury concept has been decribed as three levels (Alleres 1996, Aiello and Donovito 2006, Godei et al. 2012, Wiedmann et. al 2007, Kapferer and Bastien 2012, Wagner et al. 2015): a) inaccessible luxury; b) intermediary luxury; accessible luxury. Cosmetics companies that we consider in this paper belong to the accessible luxury. Even if is quite difficult to identify were each level of luxury starts (Kapferer and Laurent 2016), accessible luxury products create the same expectations as intermediate and inaccessible luxury products as a way to enhance one's image (Mundel et al. 2017). The question to be investigated is if in the new culturally distant markets, as China, the standardization strategy should be always adopted by luxury companies or adaptation is the more suitable solution in certain luxury industries (Zhang et al. 2012). The case of western cosmetics companies entering the Chinese market has been studied as a possible new approach to the luxury market strategy (Oswald 2010, Hodge et al. 2015).

\section{East Asian Beauty Ideal}

China is rapidly beating many records in terms of growth and development in many sectors, beauty products representing one of the most dynamic. Chinese people became in the recent years the biggest buyers of luxury products and their passion for luxury translates also to beauty purchases. However, Chinese traditional ideal of beauty differs to a high degree. Not only the ideal differs, but the adaptation to the Western stereotype, due to the natural features, is impossible to obtain.

Despite the rose of plastic surgery operations, the result has been a mixture, a composite of traditional canons and Western ones. For example wide open eyes came to be considered extremely beautiful, but the adoration of white skin persisted. The main Western companies, historically so reluctant to adaptation luxury cosmetic brands, had to take a new direction and offer products that are suited for the different skin tone and texture of Asian women and to their hair. However an analysis exclusively focused on Chinese market, without inserting in the discourse also Japan and South Korea, would not provide the complete picture and the necessary tools the comprehend the Chinese market as a single, as inserted in the East Asian region and the reasons behind certain strategies adopted by Western firms. 
Considering Vogue the most prestigious magazine we can see some signs of change. The first East Asian model, precisely Chinese, has graced the cover of French Vogue in 2011, in 2013 in the United States edition.

While Western beauty ideals has exerted high influence on Eastern beauty ideals, a new awareness and pride in East Asian ideals is happening. The appreciation of a different ideal came from the diffusion of exposure to Chinese famous and beautiful actresses. Japan has been the first country to develop a strong industry and to become the second market in the world. However the development has been dictated by the influence of Western ideals and fashions. Brand names and allure are connected with Europe. Despite the low market share of Japanese brands in Western markets they have established a status of high innovative and quality products.

China is the main driver of the actual change, supported by Korean rise. The emergence of China and Korea as powerful economies legitimates the praise of Asia beauty ideal. Since its understanding has been so crucial for Western companies in China and it is influencing Western women too. According with Kyo (2011) "The point of view of observers differs with the climate and the era, and the public taste also constantly changes. Representation of beauty too shifts dramatically with passage of time".

In all the three countries the ideal beauty is identified with the following characteristics (Cho 2012):

- White skin: the skin does not only have to be as white as possible, but also smooth and free from wrinkles and blemishes.

- High-bridged nose: noses that are not too flat and wide are favoured.

- Black hair: long black shiny hair is still preferred.

- V shape face: long and slim oval with a pointy chin is ideal.

- Double eyelids: wide-open eyes are undoubtedly the most desired feature.

- Petite figure: there is an extreme accent on thinness and most women from since an early age are victims of extreme dieting.

- Long legs: Women wear short skirts to show their legs.

Aesthetic standards vary over time. The contact with different cultures leads to changes: East Asian countries have been highly influenced by Western beauty ideals. However, by analysing the current beauty ideals in East Asia saying that women seek a Western appearance does not deliver a complete picture. There has been a selection of what is beautiful about Western women and what is not. Western influence has been a starting point that led to a new ideal for Asia. Western canons are an inspiration that is modified according to traditional criteria.

\section{Cosmetics Market In China}

Mao's regime led to the availability of only necessary hygiene products, sometimes neither that, and to an extremely weak national beauty industry. The lack of local competitors attracted the entrance of foreign companies that started to enter the market at the beginning of the Eighties, the Japanese company Shiseido being among the first in 1981. The initial absence of local competitors, 66 companies in 1980, the lack of knowledge about the products, and the high population made the Chinese market attractive from the beginning. Even if the companies that wanted to enter to market were obliged by the government to form joint ventures with local brands, local companies collapsed quickly under the rise of Western competition. According to a report of Chinese Academy of Social Sciences in Beijing in 1982 the market value amounted to \$24 millions while in 2015 it represents a market of more that $\$ 21$ billions, and it is still growing ${ }^{1}$.

\footnotetext{
${ }^{1}$ National Bureau of statistics of China 2016 (the data excludes dental care).
} 
Having depicted the Chinese beauty ideal previously, it is possible to derive the impact of Chinese culture on purchasing habits and the reasons behind the preference or low diffusion of certain categories. From what has been said so far, the consumption is driven by the desire to reach the described ideal which relies on skincare for obtaining a jade complexion, while adopting low use of makeup and fragrance, not perceived natural. Skincare is the dominant category, followed by hair care.

This paer will analyze the market as a whole in its main characteristics, and more deeply three categories: skincare, makeup and fragrance. The main reason in that skincare is the most important category, while makeup and fragrance offer many opportunities for market development strategies by Western companies. Since the use of beauty products is filtered through Chinese culture, the consumer is still not accustomed to use certain product categories.

\section{Regulation}

One of the biggest barriers that slowed the internationalization process in the past has been represented by the different regulations concerning cosmetics. Cases of poisoning due to excessive presence of mercury in skin whitening products, or burnt and irritated skin, caused mainly by local products, contributed to the preference for Western ones that are perceived as being safer. In the last years at a national level, the regulation of many the cosmetic sector is undergoing a revision and an update. The attempt is to align Chinese regulation with the UE and US ones.

\section{Taxation and import duties}

In China high import duties, taxes and other increases in sales lead to a price escalation that for for luxury goods it amounts at $20 \%$. Being Chinese active travelers this results in a flourishing "grey market". This means that people traveling buy products in other countries because they are less expensive and bring them to China. The government is aware of the impact on national economy and since the annual economic growth amounted to "only" $7 \%$ in the first quarter of 2015, the lowest in the last five years, China's State Council took measures to lower import taxes in order to push home spending and boost the economy. However, import tax is not the only tax applied on the products. For cosmetics as a whole (not just skincare) an import customs duty of $6.5 \%-15 \%$, import consumption tax of $30 \%$ and import valueadded tax ("VAT") of $17 \%$ are applied. In addition the price pyramid accounts also the addition of sellers.

\section{Distribution}

Acceding the right distribution channel has proved to be a difficult task in the past and in China it is characterized by additional challenging factors. The main one is the vastness of the territory, and the quick urbanization process. Not all the channels are present and equally favorited in all the cities. The high presence of counterfeit products is another risky factor. Except from department stores and verified e-commerce stores like Tmall, fake products are sold everywhere. Considering the fast spread of negative opinions, accidents caused by a fake product can have a bad impact on the image.

The choice of the channel depends on the brand positioning. It is important to outline that the positioning does not have to be the same as in the home country.

There are seven main channels:

1. Department stores. These are the preferred choice for high-end brands because they represent a sign of prestige. The brand selection is wide but the competition is really high.

2. Professional shops, chain stores. They offer a good shopping experience but generally only well known brands are selected.

3. Hypermarkets and supermarkets. These are the preferable channel for medium and law range products.

4. Pharmacies. The selling of cosmetics in pharmacies is an evolving and growing business. 
5. E-commerce. Almost every known brand, ranging from low to high end, uses it. Unfortunately, China Authentic Cosmetics Alliance in its first published report in 2013 reveals that more than $20 \%$ of on-line sold cosmetics is fake.

6. Beauty salons and spas. These shops offer a whole complete beauty experience.

7. Direct selling. Chinese companies are doing well considering based on relationship, well suited for Chinese culture.

Entering Chinese market requires help from local operators. Like for the registration process for which a Chinese agent is mandatory, selling through a local distributor that represents the brand is not mandatory but is the most efficient solution. The preferable route is to have more than one partner, differentiated based on geographic area. To convince a distributor to collaborate and represent the brand, to fulfill all the bureaucratic requests, requires knowledge of Chinese culture.

\section{Competition}

When the first brands entered the market in the Eighties, the percentage of foreign brands was $90 \%$. Over the years local brands started to emerge and today the percentage is around $70 \%$. The main characteristic of the Chinese market is that in almost every category the top five brands hold a market share of more than $50 \%$. The competition can be divided into foreign Western brands (France and US mainly), foreign Asian brands (Japan and South Korea) and local brands.

Western brands are targeting the luxury segment. Cosmetics is the second luxury category and has maintained an annual growth of $20 \%$. However Western brands have to face a series of disadvantages mainly imposed by the lower knowledge of the culture compared to Asian or local brands.

The main advantage of Asian brands is that their product lines are already suitable for the market. They have better knowledge about Asian skin and hair and know better the market and the culture. The products are based on innovation and traditional ingredients, known by Chinese people for millennia, and cased in packaging designed based on Asia aesthetics.

Local brands are still weak because of lack of marketing strategy and most of all because Chinese are suspicious about local brands. However, some local brand are gaining the spot in Chinese women preference. The combination of tradition and modernity is their main advantage.

Exhibit 1. brands by nationality

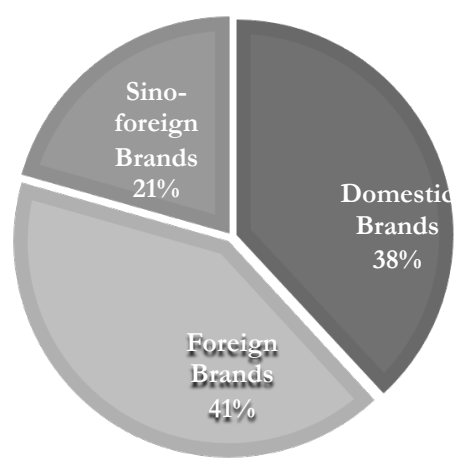

Source: Gentlemen Marketing Agency, “China Cosmetic’s Market Report”, 2014

\section{The education of the consumer}

The education of the consumer (Pontiggia and Vescovi 2016) it is an important factor for the quality of the shopping experience. Even if beauty culture has increased significantly among certain parts of the population, million people year by year become new users of some categories of beauty and cosmetic products and especially in rural areas there is still a lack of knowledge. Highly trained sellers are also a way of gaining a good reputation and brand recognition. 
The importance of "gift with purchase" and value sets

Even if it is highly popular also in the Western countries in China it assumes a cultural importance. The gifting is a distinctive trait of Chinese culture and beauty companies are aware of that. People like to buy beauty products as a present and sets are the best suited for this purpose.

\section{$I-W O M$}

Internet word of mouth and in general the on-line reputation of the brand is extremely important. The importance of the opinion of friends and of the "face" is taking a new form in the digital era. China is the country with the largest number of web users, more than 667 millions in $2015^{2}$. The consumers of beauty products belong to the highly-connected part of the population. Having a Chinese website, being active on the social media and present in the main e-malls improves considerably the reputation and prestige of the brand. Indeed, before purchasing, the Chinese consumer will likely have a browse through the major social media and on line platforms.

\section{The choice of the Chinese name}

Big multinational cosmetics company that started to enter market were well known around the world, but not in China. The first step to successfully promote the brand is to find a good corresponding brand name in Chinese. However, it is a difficult task due to the language barriers and differences. A successful brand translation should consider language, sound and meaning (Melewar 2004, Sinha 2007, Vescovi 2011). However according to Barnes, Kitchen, SpickettJones, and $\mathrm{Yu}$ (2004), a preference for the original brand name was increasing and the preference was accorded to having both the original and the translated name, approach that the multinationals follow.

\section{The impact of Chinese culture on advertising}

The influence of culture on advertising has been largely recognized (Papavassiliou \& Stathakopoulos, 1997). Companies operating on international stage can choose a standardized approach, using the same advertisement in all the markets, a localized one (targeted specifically for China) or a mix of both, adapting only certain aspects. In its research Yin (1999) has discovered that among 184 companies $77 \%$ used the third approach. There is recognition of the the cultural influence, that cannot be ignored. Desire for beauty is indeed universal, but the ideal is not. If we consider that advertising expenses can account even to $25 \%$ of the value of the sales (Estée Lauder) and that China became the largest advertising market in Asia, the way in which multinational decide to promote their products in relation to Chinese market is of essential importance. Studies conducted through interviews by Barnes, Kitchen, Spickett-Jones, Yu (2004) and by Barnes, Siu, Yu, Chan (2009) on cosmetics advertising in China, involving the metropolitan cities of China have shown that:

- The preferred media are TV and magazines, with respectively $48 \%$ and $26 \%$. The third medium is outdoor advertising.

- Regarding the use of models, in 2004 in Shenzhen a large part of respondents expressed preference for Eastern looking ones. The study of 2009, that comprehends a larger number of cities, outlined that $43 \%$ of respondents were neutral, while the preference for either Eastern or Western models were equally spread. The use of celebrities may represent an advantage and when they are Eastern it is easier to identify with them. Checchinato, Colapinto and Giusto (2013), have compared cosmetics luxury advertisements in the Italian and Chinese Vogue in order to find if a standardized approached is followed, and in particular the models used, the visual and photographic characteristics and the amount of information that the adverts provide. Their finding show that the level of standardization is $7,1 \%$. The result of these studies show that a certain degree of

${ }^{2}$ China Internet Watch 2015 
standardization is achieved, anyway complete standardization is not effective, while total adaptation could be expensive but most of all would damage brand image. A mixed approach should be followed (Seitz \& Handojo 1997).

\section{Research Propositions}

The aim of this paper is to verify if a distant culture affects the luxury cosmetics market, laeding to standardization or adaptation, by analyzing the strategies of global/multinational companies operating in China. The questions this paper will try to answer are: does the East-Asian beauty ideal influence companies's strategies? Is adaptation needed for a positive performance in cosmetics Chinese market?

The research propositions are:

Research Proposition 1: East-Asian beauty ideal influences the company's strategies.

Research Proposition 2: Marketing mix adaptation is needed in cosmetics Chinese market.

Research Proposition 3: Adaptation strategy are more effective than traditional standardization in segment market strongly affected by regional cultures and habits.

To answer these questions we conduct an explorative analysis of East-Asian beauty ideal in order to determine how it has influenced companies strategies; a survey of Chinese cosmetics market that will highlight characteristics and current trends; and an analysis of Western's companies' strategies in the market.

The choice of the companies to analyze will be dictated by their position in the global market and in China. Just before the establishment of main well known beauty brands, an article published in 1851 in the Scientific American journal entitled "Facts for the curious: female beauty" testifies that: "The ladies from Arabia stain their fingers and toes red, their eyebrows black and their lips blue... The Japanese women gild their teeth and those of the indies paint them red... Hindoo females when they wish to appear particularly lovely, smear themselves with a mixture of saffron, turmenic and grease... In China, small round eyes are liked; and the girls are continuously plucking their eye brows, that they may be thin and long" (Jones 2011).

Beauty companies have had an important role in shaping the beauty standards around the world and after decades of promotion of Caucasian ideals, a shift is happening with increasingly higher degrees of diversity in terms of models and products offered.

\section{Research Methods}

The penetration strategies of L'Oréal Paris, Estée Lauder Companies, LVMH Moët Hennesy and Olay will be analyzed. We decide to analyse these companies beacuse: a) these companies hold a strong presence in China according to companies' reports an online Chinese ranking platforms; b) All of them sell three categories: skincare, makeup and fragrance; c) All four companies have a brand ranked in the top five skincare brands in China.

Influence of the beauty ideal is signaled by: Use of local models; Product adaptation. The product is adapted when is specifically conceived for the market and not sold elsewhere and is conceived for the market but is sold in other markets too. Advertising is adapted when local models are adopted and visual and sound elements are different compared to home market. Distribution is adapted when the brand is sold outside the department stores, specialized stores and e-commerce.

According to Zou and Cavusgli (1996) the variables considered in the standardization perspectives are the product, the promotion, the distribution, and the price. These variables will be considered in addition to the presence of local manufacturing facilities (and use of traditional 
ingredients) and research centers, if local brands have been acquired or launched, the digitalization strategy and responsiveness to local trends.

The main sources of information are: official annual reports published by the companies, their institutional websites with news and official statements reported on newpapers and journal. In addition other sources composed mainly by WWD articles have been used when appropriate. The advertising campaigns have been analyzed by looking in the Vogue and Elle fashion magazines, Italian and Chinese versions, online available adverts and TV commercials. Chinese version websites and Chinese e-commerce platforms were used to see the products offered on the market, the prices and social media engagement.

Skype interviews (from 40 to 50 minutes long) with the brand managers has been done. In order to determine if the prices differ around the markets the prices listed on official website sites of the brands in China, JD e-commerce and Chinese Sephora have been analyzed. Sephora and official websites have in almost all the cases identical prices. However, as said previously, JD prices are even $40 \%$ lower. A comparison between Sephora prices In China, Italy, France and USA has also been considered. Western prices differ for certain products even to a $20 \%$. Differences regarding France and Italy are present.

\section{Main Findings}

L'OREAL.

L'Oréal, the most global brand, follows a peculiar globalization strategy: universalization. It means globalizing but respecting diversity around the world in terms of beauty ideals, routines and traditions. "The more global your company becomes, the more local your strategy has to be" is the followed strategy.

Choosing a good name translation is one of the first steps, since the Chinese name is really important for the Chinese consumer. L'Oréal's Chinese name means "Elegance coming from Europe". Lancôme's Chinese name means "Girls in the bloom of youth".

L'Oréal entered the market later than some other competitors, 1996, by established a partnership with an important Chinese Medical University, the Sozhou Medical College and founded the Suzhou L'Oréal Beauty Products company. It also started to build a new factory to answer to the forecasted development of the industry. At that time Chinese consumer were more accustomed with Europe in general than with Paris itself (while today French brands are really appreciated). L'Oréal decided to focus more on skincare, in accordance with Chinese beauty ideal. Another choice that differed from the strategies adopted in other countries, was selling L'Oréal brand as an affordable luxury. It was sold at around half of the price of a real luxury brand, in department stores of the biggest cities. The aspect of the education of the consumer was curated with trained shop assistants at the stands, since a culture regarding cosmetics totally lacked.

Brand selection and product adaptation: Since the group still lacked extensive knowledge about the consumer, the culture, the market, and the distribution it has been decided to start with few selected brands while the learning process was underway and while the consumers was becoming familiar with the proposed brands. So, in addition to L'Oréal, the group also brought the Lancôme brand to China, in 1993 and according to L'Oréal website, Maybelline New York brand in 1998 and Vicky, in the same year. With Lancôme the aim was to be the pioneer of the luxury cosmetics. Vichy completed the offer with a pharmaceutical line. Over the years new brands were added and today almost all the brands of L'Oréal's portfolio are sold in China. Even if this strategy has proven to be highly successful not all the brands perform equally well. Garnier brand was not performing as well as the others since it had a middle positioning that is not yet fully appreciated in China.

Local Production and Research: As we have seen the first production facility was open from the beginning. Other two were added in the following decade. In 2005 as a sign of commitment to the 
market the group opened a research center in Pudong, outside Shanghai. The aim is to acquire extensive knowledge about Asian skin and hair and develop products suitable for all the Asians around the world.

In a market like China in which the preference for local ingredients is so strong, acquiring domestic brands was a good strategy to strengthen its position. The company decided to acquire the domestic brand Mininurse, in 2003. According to L'Oréal statements the brand was launched in 1992 and was in the top three skincare brands in the country with market share of 5\%. L'Oréal perceived it as the ideal brand to add to its portfolio and speed the penetration of the skincare market. In 2004 another skincare brand was acquired: Yue Sai. In 2014 the biggest investment in the Chinese market took place, with the acquisition of the Magic brand, the Chinese leader in the face mask segment.

Distribution: At the beginning L'Oréal had a really limited presence, located in a small number of cities. The reasons were the limited knowledge of Chinese distribution system and the fear of having low distribution control in a not well known market/country. In particular at that time the impact of the educational factor was extremely strong and L'Oréal sold only where selected advisors could have been placed. The acquisition of the domestic brands has represented a big step into widening the distribution network. L'Oréal had access to super/hypermarkets and to tier two and three cities. Luxury brands in 2013 were sold in 972 department stores, 140 Sephora stores, 6 boutiques, 680 airport retail spaces and to more than 700 cities thanks to e-commerce.

Advertising: Big role in strengthening the brand over the years has been played by massive advertising campaigns. L'Oréal's uses extensively famous models and celebrities for its advertising campaigns and this was the strategy adopted in China too, endorsing it first ever Chinese ambassador, the actress Gong Li. Celebrities had the double role of presenting L'Oréal to Chinese women and "encouraging them to pursue beauty", while at the same time attracting the Western audience and diffusing the ideal of Eastern women. The campaigns were both in the magazines and on TV. The style of printed ads is consistent with the Western ones. The graphic style is the same and it is clearly recognizable that is part of L'Oréal campaigns. Internet becomes an essential tool and now all the campaigns have also a digital counterpart.

Digitalization strategy: the digitalization strategy is essential. New technologies, apps, social networks all offer a unique opportunity to reach new consumers, increasing L'Oréal's presence in their lives, while at the same building a stronger relationship. In China cunsumers' social media behavior is more and more crucial in collecting information and shopping. Specific Chinese social media are used.

The keys of success: The L'Oréal group has succeeded in becoming a market leader in many segments thanks mainly to its profound investment in understanding the Chinese culture, beauty ideals, consumer and market and adapting its business model consequently, adapting its offering in order to suit the Chinese aesthetic canons and was able to do that thanks to research. With the acquisition of domestic brands it moved to mass market distribution. E-commerce represents one of the biggest assets and the group engaged highly to reach more than 1000 cities with this mean. In addition travel retail shops and brand owned ones have the high merit of increasing visibility and reputation. The I-WOM, play an essential role and the focus on strengthening the relationship with the consumer. Advertising has been the main driver for increasing brand awareness and a mix of adaptation and standardization has been the chosen path. Two key brands emerge: L'Oréal and Lancôme which are the ones more engaged on line, with the strongest advertising campaigns and vast presence.

\section{ESTÉE LAUDER COMPANIES}

Brand selection and product adaptation: All the brands belong to the luxury segment, the fastest growing one. It represents $30 \%$ of the sector and luxury skincare is the fastest growing in China. The skincare brands offer different solutions and price ranges starting from Clinique to Estée Lauder and La Mer. Since it is a premium brand it is targeted to the globe trotters and indeed the 
website proposes selections of products to carrie on plane, different sets and boxes already packaged as gifts. Addition of whitening products and some targeted creams and serums, with the packaging elaborated based on Chinese preferences exists. However, the aim is to sell on a global level all the products. Estée Lauder did not acquire a domestic brand. We can conclude that Estée Lauder group does not adapt its products specifically to China to a high degree.

Local production and Research: Local production has not been established but due to the strategic importance of the market, in 2005 a research center has been opened in Shanghai. The China Innovation Institute, later called Estée Lauder Companies Asia Innovation Center, was founded in order to "help the company understand Chinese consumers' preferences, needs and interests in new trends.". In 2011 a new center was open in order to "expand the research capabilities reinforcing its strong commitment to local consumers by developing products tailored to the specific needs of Chinese and Asian skin." ${ }^{3}$. The center has the aim of exploring the differences in genetics and the responses to environment effects and ingredients in order to offer the best quality products for the consumers. In 2014 a historic brand launch was been made by the company: Osiao Asia Skin Institute. It is the first ever brand specifically developed for a particular region. Instead of acquiring a local brand, the group engaged its New-York based researchers and the Shanghai based ones worked for five years in deep studies about more than 1000 Asian women to understand the secrets of glowing skin. The products that resulted are a combination of Chinese medicine and its traditional ingredients and Western technology and science.

Distribution: Estée Lauder started by selling in department stores of the biggest cities. In 2005 the group was present in 39 department stores in 19 cities, in 58 cities in 2012 (with an increase of 20 cities compared to previous year) and 350 cities thanks to e-commerce and in 100 cities in 2014. The focus from 2009 has been on expanding to tier two, three and four cities, which is achievable mainly thanks to e-commerce. When Sephora entered the Chinese market it became a perfect partner since it offers upscale products and certainty of their original status. The company has found an innovative way of promoting its brands through pop up stores that moved on the Chinese territory. The shop has the function of increasing brand awareness but since the shop has only a temporary presence it becomes the driver of online purchasing. Travel retail completes the distribution channels and increases the sales on a global level.

Advertising and models: In 2010 the model Liu Wen become the first Chinese to be signed by the brand, in the role of global brand ambassador. Later that year a model with dark skin joined the trio completed by a Polish model with fair skin, blue eyes and blonde hair. Choosing a local model and propose localized campaigns was not an option but having a trio of models that could represent all the women around the world was a move that was favorably received. Liu Wen represented the company around the world but was particularly present in all the campaigns for China and represented the brand in new shop openings and events.

Digitalization: The contents on websites are engaging and provide many tips. For example, the Chinese Clinique website is visibly different from the Italian one. It has a more youthful feel and famous personalities, like bloggers are featured. The skin diagnosis system is adopted also on Tmall, making the purchase of skincare easier and customized. An example of how the brand is trying to get close to younger generations and Asian consumers is the collaboration with an LA based Korean fashion and beauty blogger in a series of on line tutorials and most of all the appointment of Irene Kim as a global contributor. A good internet reputation depends also on the level of engagement on social media and some of the brands like Clinique is present on Weibo and WeChat where posts a least an article a week.

The keys and the obstacles to success: Being a luxury Western brand in the Chinese market represents an advantage due to the aspirational component and the preference for luxury skincare products. The skincare brands from the group offer a variety that is able to reach every age and price segment (considering the luxury price range). The focus on travel retail and digital component

3 Estée Lauder Companies Report 2012. 
are also suited for Chinese market. The investments done for the future which is focusing on developing makeup and fragrance divisions and the launch of targeted skincare brand may lead to very positive results. The biggest obstacle is represented by the distribution. While L'Oréal is able to reach 1000 cities, Estée Lauder just reached 300. The decreasing appeal of department stores represent a big threat.

The initial reluctancy to sign a Chinese model has translated in the model becoming a global ambassador. Since makeup and perfume are still undeveloped, Estée Lauder group is investing in these categories to establish itself as a leader in the premium makeup range. Indeed, the plan is to launch fragrances specifically conceived for Chinese market.

\section{LVMH Moet HenNessy Louis VuitTon SE}

Guerlain brand entered the market in 1993, while the exact year of Dior's entry was not possible to find but it can be assumed that it may be similar to Guerlain's. The other brands entered the market in the recent years.

Production and research: Vertical integration is pursued in all the divisions of the LVMH in order to have more control over the operations and assure the quality standards that distinguish a luxury brand. The Chinese affiliate is a manufacturing and distributing facility. The company reports extensive collaborations around the world with various centers and universities, but the official research centers are located in France.

Product lines and adaptation: In terms of product adaptation Dior and Guerlain offer a whitening line, respectively Diors now and Blanc Perle, in order to meet the Chinese preference for fair skin. By comparing the Dior products present on the Chinese and on French Sephora, the following figures emerge: the perfume segment comprehends 30 products for China and nearly 90 for France, 65 makeup products agains 95 and 51 skincare products against 47. It can be concluded that the offer is adapted in the sense that is reduced according to Chinese preferences. Gurlain's offer shows the same picture: perfumes and makeup are downsized and with a changed mix, while skincare prevails. It can be concluded that overall the adaptation of the products is limited.

Distribution: Being the Sephora chain part of the group, the brands are present in all the Sephora stores. In addition the most exclusive department stores are selected, in order to keep the exclusivity high. The stores increase the visibility and communicate the essence of the brand. Since many products evoke the fashion line, experiencing the brand in all this lines in the same place makes a unique shopping experience. Dior opened its third cosmetics boutique, after Paris and Tokio, in Shanghai which represented a sign of commitment to the market. Guerlain on the other hand, but have a spa in Shanghai, a really exclusive location in which the consumer can experience all the iconic products of the brand. Neither of them have an e-commerce on their websites, it is not a policy of such iconic brands, which in a market such as China is a big limit.

Advertising: The magazines are still today really important, indeed the most advertised brands are Lancôme, Dior, Estée Lauder and Guerlain. Part of the mix are also banners, billboards and the windows of the stores themselves. The Dior TV campaigns are in the typical Chinese style, considering the colors, the music, the accent on the way the products work inside the skin. Indeed the company signed with a local agency in Shanghai to handle Dior's online campaigns in order to make them more appealing to the Asian public. A revolutionary step concerning the models was also done by the brand. Both the campaigns featured Asian models, that appeared only in Asia.

Digitalization: Both premium brands have a Chinese website, which main object is to tell the history, the excellence of the brands. Dior has recently dedicated a section which explains the negative effects of pollution of big cities on the skin. The online channel is also used for the advertising campaigns. Both are present on Chinese social media. The Benefit's website is quite unique. It is the first one in non latin alphabet, but the company wanted to have control over the content and to be able to do it from Los Angeles so hybrid multichannel system has been adopted that permit allows also to pay at delivery, preferred in China, and mobile commerce will be implemented. The Makeup Forever website maintains the same structure as the original but the 
images change and more Asian models appear. The makeup school and academy is also adapted and Chinese makeup artists are involved.

Sephora: Sephora, acquired in 1997, is today the biggest beauty retail chain in the world, with more than 2000 shops in 30 countries worldwide. The concept of the store is quite different compared to traditional beauty shops: the consumer is left free and helped at request. Sephora entered in China ten years ago and in 2013 opened its biggest flagship store in Asia, in Shanghai. According to the LVMH Annual report 2015 the number rose to 194 stores. The Sephora Shanghai shop carries 3 Chinese and 17 Asian brands and the biggest Chinese group Shanghai Jahwa owned a 19 percent stake in Sephora's China operations. The popularity of Asian brands is growing and Sephora had to adapt. The Shanghai store represents perfectly the Chinese cosmetics market and reflects a profound study conducted by the retailer.

Keys of success and limits: The LVMH group is an epitome of luxury at its highest around the world. However, this status poses many limits to the adaptation and, compared to the other groups analyzed, the degree of adaptation to the local needs is the lowest. Indeed this translated in not being the market leader for skincare, but in solid position in the makeup segment and leader in the fragrance department, the strongest of the group. The prevalence of color cosmetics and perfumes did represent at the moment a limit as well as the absence of a local research center and the absence of specifically studied products for Asian skin. The lines of all the analyzed brands have mainly been downsized. Sephora wins as the most adaptive brand and with strategies that reflect the market, which is the result of being dislocated physically around the country and having the possibility to study the consumer. The brands have succeeded in communicating their origin and their history, their Western status represents an advantage but is losing its importance in the latest years.

\section{P\&G OLAY}

P\&G followed a different strategy compared to the usually adopted ones at that time: it studied the market for four years before officially starting to sell its products in 1989 and started advertising the brand two years earlier. It first entered Hong Kong in 1987 and then Mainland China. It established a joint venture with a local producer operating in different business, toiletries being one of them. The name can be translated as "Oil of pure orchid" and is composed by a character associated to jade and one which means the rarity of the orchid. The importance of Asian markets is testified by the decision to move the headquarters of the personal and skincare unit from Cincinnati to Singapore, in order to be closer to the key market.

Product adaptation: Olay has a differentiated offer based on product lines targeted for teenagers, young women, older women and with different skin concerns ranging from acne, to wrinkle to the whitening lines. It can be concluded that the degree of adaptation is high.

Production and Research: Both production centers and R\&D centers are present in China. They represent the key factor for offering a product customized for the consumer. Over the years P\&G has collaborated with local authorities, universities, research centers in order to understand the market, consumers' habits, preferences and skin and hair. In all its operations, according to the company, the choice was on local employees. Indeed $97 \%$ of workers in China, are Chinese. They represent a crucial asset, because they themselves are consumers and can provide extensive knowledge on the market, culture and habits. The research is the base for a successful offer.

Distribution: The distribution strategy aims to enable the brand to be highly available. Olay is sold in department stores, hyper-markets, specialized stores and online. In the latest years the focus is on reaching even the smaller cities and rural areas. $P \& G$ has been one of the first to enter the market and aims at being the first to reach the smaller realities in order to benefit from the first comer advantages. Indeed in 2010 a new distribution facility, highly automatized center that will speed the distribution in the region.

Advertising: Aggressive advertising has also contributed to make the products successful. From lifestyle magazines to high dose of tv commercials to billboards. From the beginning, only Chinese 
models appeared on the campaigns and websites. Some of them are famous and one of them was the later Estée Lauder global ambassador. The product range is specifically conceived for Chinese women and the feature of Western models would not be able to communicate it effectively.

Digitalization: The website comprehends the e-commerce, number for direct assistance and space for requests by the consumers which is a high-quality customer service. On Tmall Olay has also launched an extremely popular initiative where consumers can sent personalized pictures with the products and win prizes. Olay presence on social media is good. It reports it qr codes for we chat on the site is really engaged both on Weibo and Wechat.

Keys of success: Olay's strategy has proven to be extremely successful thanks to an adaptive approach that included extensive study in loco of the market and consumer that resulted in products specifically targeted for the Chinese consumers, strong advertising through local models and high availability that built brand awareness and desire for purchase, that is finalized thanks to affordable prices. In addition good online reputation, customers service, proximity to the consumers has been reached using the digital tools.

\section{Discussion}

The evidences and the findings, concerning the four case studies, highlight different solutions and strategic approaces to the distant culture markets, in particular East-Asia. Nevertheless, there is a common basic strategy concerning the alternative between standardization and adaptation in the cosmetics industy: adaptation. This strategic solution has been adopted in different ways, different depth, different timing. More precidely, the research proposals can be discussed as follows.

RP1: East-Asian beauty ideal strongly influences the company's strategies is confirmed.

Considering the variables which are use of local models, product adaptation and presence of R\&D centers we can say that except from LVMH group that does not have an R\&D center all the companies must offer products suiting the ideal and all of them have used Asian models. The focus on skincare, the lighter makeup products, the different assortments connected with the different bauty ideal, the development of new specific products with ingredients of Chinese cosmetics tradition, the communication strategy focused on Asian models are all clear evidences of the influence of East-Asian beauty ideal on the cosmetics companies.

The companies had to understand the market, the consumer, the culture and start from the results in order to build an offer that is valuable in the eyes of the Chinese consumer. The brands that choose to adapt their offer to the dominant ideal succeed.

RP2: marketing mix adaptation is necessary for a positive performance in cosmetics Chinese market is confirmed. Three successful cosmetics groups have been analyzed and one medium successful one. From the analysis of the companies By comparing market characteristics and trends with the companies results on the market and their strategies it can be said that L'Oréal's and Olay's strategies are the most effective. An adaptive strategy that targets different consumer segments leads to best results. L'Oréal is able to reach every desire of the consumer with one of its brands. Olay has a limited option being a single brand, but its differentiation into lines has the same aim. Estée Lauder is pursuing the highest degree of adaptation that its luxury status allows. In particular local models, adapted products are incorporated into global strategy. The local model becomes the global ambassador, products that are conceived for Chinese markets are then sold worldwide. In addition, in order to meet the Chinese growing preference for traditional ingredients a new brand has been launched, since too much adaptation is not typical for a luxury company.

The LVMH, even if it has adapted certain components of its marketing mix, can still be considered less adaptive compared to the other groups. Brands have expanded their lines to offer products suited for the Chinese market. They also propose some products exclusive to China. 
Overall the key factors for success are: a) effective digital strategy adapted to Chinese market; b) Asian spokespeople; c) offering products targeted for the market; d) a local research center; this aspect is particularly important, only LVMH does not have a local R\&D; e) Use of traditional ingredients and responsiveness to trends, the most responsive brand is L'Oréal, the market leader.

RP3: also in some luxury industries, adaptation strategy can be more effective than standardization one, as commonly pursued is confirmed. Despite the managerial approach to the different markets of the luxury companies is devoted to globalization and follows a mainstream that is standardization, China represents a big challenge to this mindset. Even a company as LVHM, so deeply sunk in luxury managerial culture has been forced to move towards adaptation by the Chinese consumer's expectations. It seems evident from the field analysis that the more the luxury culture is adopted by a company the more difficult is to accept to consider cultural differences in the differnt markets. Actually the most flexible companies are the ones (Olay and L'Oréal) having also a less exclusive approach. Luxury culture is extremely connected to the producer point of view than the consumers' one.

\section{Conclusions}

The luxury brands, once resilient to adapt, had to it to some degree and the companies that adapted the most adaptive strategies are market leaders in their categories. However, competition from local and regional brands is increasing and the question becomes: will the Asian brands eventually win the Chinese markets? If they do, how will it translate on Western markets? Overall the impact of China on the industry has been huge: Western population is more familiar with the Asian beauty ideal and demand for Asian products is increasing.

The main three regions in which a company must be competitive in order to be globally successful are North America, Europe and China (Ohmae 1989).

In the case of cosmetics industry this was true. All the companies started by establishing strong positions in their home markets, on which they depended strongly. None of them could establish a strong position in foreign markets in which strong local players were present. When the companies entered the Chinese market they were all dependent on their US and Europe operations. However, by analyzing the segmentation of companies's sales a strong change is evident. Estée Lauder has moved from having $65 \%$ of sales coming from the United States to having a balanced performance in all the major markets. Asia-Pacific region accounts today for around $20 \%$ of sales for all the companies. The incidence of domestic market is losing importance year by year and companies are focused on conquering the emerging markets, which happen to have different beauty ideals. Indeed other Asian markets share the preference for lighting products. While Europe and US shared common beauty canons, all emerging markets despite being influenced by Western ideals, have different type of hair, skin and live in different climate conditions.

The establishment of local R\&D centers signals a profound change that implies the willingness to adapt to local needs and diversity. Only the LVMH still relies on the France center which a proof that luxury companies still promote "universal needs" that do not require strong local adaptation.

From the first international expansion attempts, it has emerged that beauty is strongly influenced by culture. The difference in beauty ideals and practices is the major obstacle for marketing the same products all around the world. The companies were less prone to adaptation and therefore the domestic market was dominant. Indeed, in China large product adaptation was necessary in order to succeed. Contemporary Chinese beauty ideal is a result of centuries of evolution in which some characteristic has changed, while some survived the passing of time.

Beauty is part of a culture and standardized products are difficult to market in the country where a beauty ideal strongly differs from that of the domestic market of the company. The cultural influence has also shown through the necessity to choose a Chinese name and adapt the advertising 
strategy. An interesting cultural aspect is also the difference existing in the male use of skincare products. While in the West men have a prejudice toward cosmetics, Asian men have historically used skincare and makeup like women. Men segment is the highest in the world and all the companies have developed dedicated lines.

Cosmetics companies belong to the multinational types more than the global one, as normally happens for luxury products. So adaptation prevails on standardization.

Domestic markets represent today only a part of companies' sales and developed markets are losing their incidence and the importance of emerging markets is growing. The companies that will be able to offer products that are significant for the populations of these countries will be the winners. An approach toward local adaptation and orientation to emerging markets is evident in companies. China has shown a new direction to cosmetics companies. Before the Nineties all the companies were highly dependent on American and European markets and they shared a similar beauty ideal represented by women with blue eyes and blond hair. There was the belief that beauty is universal. The willingness to adapt the marketing mix is particularly challenging for luxury companies. The brand is the most important asset and local adaptation would represent a threat in terms of image. However, China forced the companies to review the tratitional approach.

China was eager for Western products which united to the safety problems of local brands and high quality of Western ones, represented a strong advantage. However, Western products had to suit Chinese skin. Chinese women did not want to imitate blindly Western women. Cosmetics companies from Europe and USA had to adapt to the market in many ways and to use the knowledge acquired in the previous decades. First, they had to establish a strong brand also in China. It was achieved through the education of the consumer, strong efforts in advertising and the offer of innovative products that suited Chinese women.

Today companies have to offer products that are of high quality and significant for the Chinese consumer. Western origin does not represent a strong bonus anymore. It is signaled by the success of some Western brands that sell natural and pharmaceutical products. Their success is not dependent on their origin but on the fact that they respond to a precise preference.

In the last years local and regional players, mainly from Korea are increasing. Their success is based on their correspondence to local tastes which means whitening products and natural ingredients, possibly belonging to Chinese medicine. Connection to tradition coexist with modernity, represented by highly connected consumers that travel the world.

China has been a pilot country that has contributed to the transformation of the industry. The awareness that the desire for beauty is universal, but beauty has different declinations depending on the country has definitely matured. Standardized approach is not possible and ince the importance of new emerging markets companies will have to find ways to adapt while still remaining globally consistent.

\section{References}

Aiello, G. Donvito, R. (2006) 'L'evoluzione del concetto di lusso e la gestione strategica della marca. Un'analisi qualitativa delle percezioni sul concetto, sulla marca e su un prodotto di lusso", Marketing Trends, Università Ca' Foscari Venezia.

Alleres, D. (1996) Luxe... Stratégies-marketing, Economica.

Barnes B. R., Kitchen P. J., Spicket-Jones J., Yu Q., Investigating the impact of international cosmetics advertising in China, International Journal of Advertising, 23, pp. 361-387 
Bartlett C. A.; Goshal S. (1991) "Global Strategic Management: Impact on the new Frontiers of Strategy Research”, Strategic management Journal, vol. 12.

Birkinshaw, J.; Morrison, A.; Hulland J. (1995Structural and competitive determinants of a global integration strategy, Strategic Mangement Journal, vol.16, issue 8.

Cho K., "The search for the beautiful woman. A cultural history of Japanese and Chinese beauty", Rowan and Littlefield publishers, Inc., 2012, pag. 302

Collins, D.J. (1991), "A Resource-Based Analysis of Global Competition: theCase of the Bearings Industry", Strategic Management Journal, Vol. 12.

Ghosh, A, Varshney, S. (2013) "Luxury Goods Consumption: A Conceptual Framework Based on Literature Review”,Apr-Jun, , South Asian Journal of Management,_Vol. 20, Issue 2.

Godey, B.; Pederzoli, D.; Aiello, G.; Donvito, R.; Wiedmann, K-P.; Hennigs, N. (2013) “A crosscultural exploratory content analysis of the perception of luxury from six countries", Journal of Product \& Brand Management. 2013, Vol. 22 Issue 3.

Hamel G., Prahalad C.K. (1994); Competing for the future, Harvard Busines School Press.

Hodge, A. C.; Romo, Z. G.; Medina, I. G.; Fionda-Douglas, A. (2015) "Consumer-brand relationships within the luxury cosmetic domain”, Journal of Brand Management, Oct, Vol. 22 Issue 8 ,

Jones J., "Beauty Imagined: A History of the Global Beauty Industry", Oxford University Press, February 2011.

Kapferer, J-N. Bastien, V. (2012) The Luxury Strategy: Break the Rules of Marketing to Build Luxury Brands, Kogan Page

Kapferer, J-N.; Laurent, G. (2016) "Where do consumers think luxury begins? A study of perceived minimum price for 21 luxury goods in 7 countries", Journal of Business Research, Jan, Vol. 69 Issue 1.

Lages, L., Abrantes, J., \& Lages, C. (2008). The STRATADAPT scale: a measure of marketing strategy adaptation to international business markets. International Marketing Review, 25(5),

Levitt T., (1983) "The Globalization of Markets", Harvard Business Review.

Melewar T.C., Meadows M., Wenqiang Z., Rickards R. (2004) "The influence of culture on brand buiding in the chinese market: a brief insight", Journal of Brand Management, vol. 11, July, Issue 6.

Mundel, J.; Huddleston, P.; Vodermeier, M. (2017) “An exploratory study of consumers' perceptions: What are affordable luxuries?" Journal of Retailing \& Consumer Services, Mar, Vol. 35,

Ohmae, K. (1989) “Managing In A Borderless World”, Harvard Business Review, May-June

Oswald, L. R. (2010), "Developing Brand Literacy among Affluent Chinese Consumers A Semiotic Perspective", Advances in Consumer Research, Vol. 37.

Porter, M. (1996) "What is Strategy?", Harvard Business Review, Nov-Dec.

Quelch A. J., Hoff J. A., (1989) “Customizing Global Marketing”, Harvard Business Review, N³, (May June).

Theodosiou M. and L.C. Leonidou, 2003, Standardization versus adaptation of international marketing, International Business Review, 12(2), 141-171.

Vescovi, T. (2011) "Strategie di marca per i prodotti italiani in Cina", Micro \& Macro Marketing, Vol. 20, n.1.

Sinha K. (2007), "The Challenge for Brands in the Other China”, China Business Review, September/October.

Wiedmann, K., P. Hennings, N., Siebels, A. (2007), Measuring consumers' luxury value perception: A cross-cultural framework, Academy of Marketing Science Review, Vol. 11.

Yip, g. (1995) Total Global Strategy, Prentice Hall.

Zhang L., Yanqun H., "Understanding luxury consumption in China: Consumer perceptions of bestknown brands", Journal of Business Research 65 (2012).

Zou S., Cavusgil S. T., (1996) "Global strategy: a review and an integrated conceptual framework", 
Wagner, B.; Wilson, J.; Vescovi, T. (2015) "Exploring the relationship between luxury brand personality, store personality and consumer charact eristics", Marketing trends, Ca' Foscari University of Venice.

\section{DATA SOURCES}

Datamonitor Industry Profile, "Fragrance in China", 2004, 2005, 2006, 2007, 2008, 2009, 2010, 2011, 2012

Datamonitor Industry Profile, "Make up In China", 2004, 2005, 2006, 2007, 2008, 2009, 2010, 2011, 2012

Datamonitor Industry profile: "Skincare in China", 2014, 2015

L'Oréal Annual Report, 2002, 2007, 2012, 2013, 2014, 2015

Market Line Industry Profile, "Frangrance in China", 2012, 2013, 2014, 2015

Market Line Industry Profile, "Personal Care in China", 2014, 2015 